\title{
In silico approach for future development of subunit vaccines against Leptospira interrogans serovar Lai
}

\author{
Rakesh S., Pradhan D. and Umamaheswari A. *
}

*SVIMS Bioinformatics Centre, Department of Bioinformatics, SVIMS University, Tirupati, A.P., India - 517 507, svims.btisnet@nic.in, amineni.maheswari@gmail.com, Ph: +91- 877-2287727.

\begin{abstract}
Leptospirosis continues to have major impacts on people of developing countries with inestimable morbidity and mortality. As current leptospirosis vaccination is relatively unsuccessful, development of efficacious vaccines through novel means became utmost priority for prevention of frequent outbreaks of the disease. Herein, MHC class II restricted peptide epitopes were identified from pathogenic Leptospiral membrane proteins to suggest T-cell epitope driven leptospirosis vaccines through reverse vaccinology. The proteome of Leptospira interrogans serovar Lai was screened to select 137 membrane proteins. Jemboss Antigenic server was employed to find antigenic peptides, followed by ProPred analysis to predict 30 short peptides having strong binding affinity with HLA DRB1*0101, DRB1*0401 and DRB1*1501 alleles. Predictions were revised to pick antigenic peptides with same core region binding with the selected HLADRB1 alleles and ten such peptides were found from seven proteins. Further, to confirm the interaction at structure level, Leptospira excinuclease ABC subunit B protein having short T-cell antigenic peptide (133REDVVIVSSVSCIYGLG-149) was modeled using Modeller9v7. The model reliability was evaluated through Procheck, ProSA and ProQ. Docking calculations for selected HLA DRB1 alleles (receptor) and modeled Leptospira excinuclease ABC subunit B protein (ligand) were carried out using Hex 5.1. The protein -protein interaction revealed that the core region (136-VVIVSSVSC-144) of the antigenic peptide (133REDVVIVSSVSCIYGLG-149) was well interacting with the receptors. Through the reverse vaccinology approach and docking studies, the short antigenic peptide 133-REDVVIVSSVSCIYGLG-149 of Leptospira excinuclease $A B C$ subunit $B$ is proposed as a potential novel $T$-cell driven subunit vaccine against leptospirosis.
\end{abstract}

Keywords- Leptospirosis, reverse vaccinology, subunit vaccine, HLA DRB1, T-Cell epitopes

\section{Background}

Leptospirosis, caused by the spirochete Leptospira, is a major public health concern and has now been identified as one of the emerging infectious diseases worldwide. The spectrum of human disease caused by leptospires is wide, ranging from subclinical infection to a severe syndrome of multiorgan infection resulting in high mortality [1]. The symptoms of leptospirosis are extremely broad from meningitis, pneumonitis, hepatitis, nephritis, pancreatitis and erythema nodosum [2]. In 5 to $15 \%$ cases, multiple organ damage is reported and the mortality rate has been shown to be 5 to $40 \%[3,4]$. Annual incidence reports of leptospirosis vary from 0.53 per $1,00,000$ in tropical countries to 0.04 per $1,00,000$ in developed countries [5]. People exposed to recreational activities, farming and post flood conditions are at major risk of getting infected through contaminated water, rodents or pets $[6,1]$. High prevalence of Leptospiral antibodies was observed in rural areas (11.34\%) than in urban areas (3.08\%) [7]. Leptospirosis seroprevalence in various occupational groups revealed sanitation workers were frequent victims $(42.7 \%)$ followed by sugarcane workers $(39.4 \%)$ [8]. Number of animals being acting as hosts, acquiring of infection can have considerable economic implications in developing countries like India. Leptospirosis vaccines are of low efficacy, have an unacceptable side-effect profile, do not induce long-term protection, and provide no cross-protection against the different serovars of pathogenic Leptospira [2]. Hence developing efficacious and long term cross protective human vaccines against leptospirosis is certainly a goal of the research community and would undoubtedly save many thousands of lives each year. The advent of whole-genome sequencing changed the way to think about vaccine development, enabling the targeting of possible vaccine candidates starting from the genomic information of a single bacterial isolate, with a process named reverse vaccinology [9]. Reverse vaccinology is an in silico discovery based system used to retrieve surface-exposed proteins in a reverse manner, starting from the genome [10]. Application of genome sequence data and Bioinformatics tool for the development of peptide vaccines for infectious diseases has gained momentum in recent years [11]. T-cell epitopedriven vaccine concept is an attractive one that is being successfully pursued in Chlamydia trachomatis and Chlamydia pneumoniae [12] and Mycobacterium tuberculosis [13-15]. The complete genomic sequences of four pathogenic Leptospira (L. interrogans serovar Lai str. 56601, L. interrogans serovar Copenhageni str. Fiocruz L1-130, L. borgpetersenii serovar Hardjo-bovis JB197 and L. borgpetersenii serovar Hardjobovis L550) [16-18] allow both comprehensive and more focused searches for factors involved in virulence that could act as hopeful antigens. The identification of surface proteins conserved among pathogenic leptospires has become major focus of leptospirosis research to generate cross 
protection across different serovars. Our goal to develop T-cell driven subunit vaccine is aided by the experimental evidences deciphering Leptospiral outer membrane proteins (OMPs) inducing cell-mediated response in mice [19]. Since activation of CD4+ helper $\mathrm{T}$ cells was essential for the development of adaptive immunity against pathogens [20], identification of T-cell epitopes would significantly add to the development of novel subunit vaccines and immunotherapy against leptospirosis. Cell mediated immune response efficiency is associated with antigen specificity, diversity and human leukocyte antigen (HLA) alleles [21]. The HLA alleles are cell-surface glycoproteins that bind antigens in the form of short peptides and present them for recognition to $T$ cell receptors on the cell surface of CD4+ T cells [22]. Naturally processed peptides isolated from HLA alleles are usually 15-25 residues long [23, 24].The central region of these peptides interacts directly with HLA alleles, typically with specific recognition of an approximate nine-residue stretch [25]. In this study we have adopted a systematic in silico approach to identify potential HLA DRB1 (HLA DRB1*0101, DRB1*0401 and DRB1*1501 those are occurring at an allelic frequency $20-50 \%$ [14]) binding peptides from surface proteins of Leptospira interrogans serovar Lai 56601. Computational tools such as Jemboss antigenic server and ProPred were used systematically for this purpose. The Leptospira excinuclease ABC subunit B protein 3D model was generated using Modeller9v7 and validated through Procheck, ProSA and ProQ. Further, the HLA allelic interaction of subunit Leptospira excinuclease $A B C$ subunit $B$ protein was confirmed using $\mathrm{Hex}$ 5.1 .

\section{Materials and methods \\ Leptospiral membrane protein dataset}

The whole genome of Leptospira interrogans serovar Lai, with annotated protein sequences is available at EMBL/GenBank. The genome consists of large chromosome I with accession number-AE010300 and small chromosome II with accession number-AE010301. Surface-exposed antigens are susceptible to antibody recognition and T-cell induction hence these are the most suitable vaccine candidates [26]. Thus, potentially surface-exposed proteins of $L$. interrogans serovar Lai were retrieved from the National Centre for Biotechnology Information (NCBI) ftp server with evidences of Leptospira OMPs inducing cell mediated immune response in mice [19].

\section{Prediction of Antigenic peptides from membrane proteins}

Identification of potential antigenic peptide from membrane proteins is important for vaccine development. Jemboss is a graphical user interface (GUI) to the European Molecular Biology Open Software Suite (EMBOSS) package for molecular biologists [27]. Antigenic server of Jemboss uses a semi-empirical method for the prediction of antigenic regions in a protein based on the physico-chemical properties of amino acids and their frequency of occurrence in experimentally known segmental epitopes [28]. The antigenic peptides in outer membrane proteins and $A B C$ transporter proteins were identified using the Antigenic server. Class II HLA molecule bind peptides of length 15-25 residues $[23,24]$ of which a central region of nine residue stretch flanks directly with HLA allele. Thus, peptide sequences less than nine residues were ignored.

\section{Prediction of HLA binding peptides}

Subunit vaccines are an important part of vaccine design strategy. It is well established that $T$ cells play a critical role in inducing immune response against foreign antigen. But for their activation the antigenic fragment must bind to $\mathrm{MHC}$ molecules. Thereby predicting which antigenic fragment can bind to $\mathrm{MHC}$ molecule is the first bottlenecks in vaccine design. The ProPred web interface allows users to predict MHC Class-II binding regions in antigen sequence [29]. ProPred was derived from the TEPITOPE, a matrix based computer program. It was developed for 51 HLA DR alleles by extracting the matrices from pocket profile database. The server employs amino acid position coefficient tables deduced from literature by linear prediction model [30]. A threshold of $3 \%$ was fixed to reduce the rate of false positives. Predictions were performed for alleles DRB $1{ }^{*} 0101,0401$ and 1501. Our analysis was restricted to these alleles since they have high coverage among different populations and their crystal structures determined by X-ray crystallography are available at the protein databank (PDB). The predicted epitopes were only kept if they were predicted to bind to selected three HLA-DRB1 alleles during ProPred analysis. The prediction was further revised to include antigenic peptides with the identical core binding with the selected HLADRB1 alleles. The average ProPred scores were calculated to rank the antigenic peptides.

\section{Molecular modeling of Leptospira excinuclease $A B C$ subunit $B$ protein}

Structural homologous entries were obtained for Leptospira excinuclease $\mathrm{ABC}$ subunit B protein through local alignment search using Blastp (Basic local alignment search tool) [31] against protein data bank (PDB) [32]. Leptospira excinuclease $A B C$ subunit $B$ protein, is an important protein involving in nucleotide excision repair and is human non-homologous. The protein is homologous among four pathogenic leptospires and the antigenic region (133- 
REDVVIVSSVSCIYGLG-149) is $100 \%$ conserved. The Blastp alignment was further refined using sequence alignments in ClustalX [33]. This alignment was used for comparative modeling to built $3 \mathrm{D}$ model by satisfaction of spatial restraints using Modeller9v7 [34]. A total of 20 Leptospira excinuclease $A B C$ subunit $B$ protein $3 D$ structures were predicted based on crystal structure of 2D7D. Subsequently, the best Leptospira excinuclease $\mathrm{ABC}$ subunit $\mathrm{B}$ protein model (structure with lowest DOPE score) was validated using Procheck [35], ProSA [36] and ProQ [37]. The protein 3D model was then submitted to Protein Model Data Base (PMDB) [38] that collects 3D models obtained by structure prediction methods.

\section{Protein-protein docking}

Docking predicts the binding mode of one molecule with the other molecule at a preferred orientation to form a stable complex. Hex is an interactive molecular graphics program for calculating and displaying feasible docking modes of pairs of protein and DNA molecules [39]. Hex is distinguished from other programs as it uses spherical polar Fourier correlations to accelerate the docking and superposition calculations. HLA DRB $1{ }^{*} 0101, \mathrm{DRB} 1{ }^{*} 0401$ and DRB $1{ }^{*} 1501$ structures were downloaded from PDB and defined as receptor excluding the endogenous antigenic peptides. The modeled Leptospira excinuclease ABC subunit B protein was defined as ligand. Shape complementarity only correlation type with a default grid spacing of $0.6 \AA$ was used to calculate docking free energy. The receptor and ligand were allowed for total possible rotational increments about their own centroids. The steric scan and final search parameters were set to 20 and 25 respectively to suit well for docking calculation of modeled structures. From the 10,000 sorted lowest docking energy solutions best 2000 orientations were retained in 500 clusters for viewing the mode of protein-protein interaction.

\section{Results and discussion}

The whole annotated protein sequence data of Leptospira interrogans serovar Lai consists 4357 and 367 encoded by two chromosomes. We have selected 137 immunogenic outer membrane proteins including $A B C$ transporter proteins from the protein sequence data. The selected 137 protein sequences were used as a dataset for the identification of peptide antigenic regions using Jemboss Antigen server. Through this process we have extracted 929 antigenic peptides from 137 membrane proteins. The least score for the predicted antigenic peptide sequence was found to be 1.0 and maximum score was 1.312 . The antigenic peptide sequences up to a maximum length of 98 residues were obtained. The data were limited to 30 based on the antigenic score.
The resulted 30 antigenic peptides were being obtained from 24 proteins, thus the immunogenic protein dataset was cut down to 24 proteins. The 30 antigenic peptides were further screened to predict HLA DRB1*0101, 0401 and 1501 binding regions using ProPred web server. Dass and Deepika (2008) reported 30 specific HLA binding peptides for potential design of vaccine candidates against diphtheria following similar procedure. The screening of peptide bindings to HLA DRB1*0101, 0401 and 1501 using ProPred identified a list of 10 peptide sequences from 7 proteins, each peptide sequence having common core epitope region binding with the three HLA DRB1 alleles (Table 1). Thus the study was confined to seven proteins for potential vaccine candidate design. The seven proteins were queried against PDB using Blastp to find structural homologues. Six proteins were omitted from comparative modeling studies, since they do not hold good template with significant E-value and posses lesser identity with gapped alignment. The crystal structure 2D7D was identified as structural homologous protein showing $60 \%$ identity with Leptospira excinuclease $A B C$ subunit $B$ protein. The target and template protein sequences were aligned using ClustalX "Fig. (1)" and generated an alignment file to develop Leptospira excinuclease ABC subunit B protein model using Modeller9v7. Modeller calculates three-dimensional (3D) model of a protein by optimally satisfying spatial restraints derived from the alignment and expressed as probability density functions (pdfs) for the features restrained. We have developed a set of 20 models of Leptospira excinuclease ABC subunit B protein. The model with least density optimization potential energy (DOPE) score was selected for validation "Fig. (2)". The Procheck validation report of the Leptospira excinuclease ABC subunit B protein model had shown $93.6 \%$ residues in most favored region and $6.3 \%$ residue in allowed region "Fig. (3)". This outcome was compared with the validation report of template structure (2D7D) which has shown 93\% residues in most favored region and $7 \%$ residues in allowed region (Table 2). These results suggest that the model is valid with good stereochemical quality. Validation of Leptospira ABC subunit B protein through ProSA and ProQ web servers revealed that the predicted model was highly reliable. The model ProSA Z score value -10.19 was well within the range of native conformations of crystal structures of similar length while individual residue energies were largely negative expect for some peaks in the middle region "Fig. (4A) and (4B)". LG score $>4.0$ is expected from ProQ model validation server for an extremely good quality model. The efficiency of ProQ server prediction increases by $15 \%$ when the $3 \mathrm{D}$ models evaluated along with their secondary structure. A high confidence 
secondary structure predicted through PSI-PRED [40] while submitted along with Leptospira excinuclease $A B C$ subunit $B$ protein model in ProQ had revealed a LG score of 5.038 i.e. well above the LG score for an extremely good quality model. To check the compatibility of Ca chain of Leptospira excinuclease $\mathrm{ABC}$ subunit $\mathrm{B}$ protein with the template, superpose command was run in Modeller9v7 and Ca RMSD was observed to be 0.66 A0 reflecting the high structural conservation between the two proteins. Through this analysis, it can be concluded that the Leptospira excinuclease $A B C$ subunit $B$ protein model generated in the present study is reliable to analyze protein-protein interactions. With all these evaluations the predicted Leptospira excinuclease $A B C$ subunit $B$ protein model was submitted to PMBD and it has accepted the model with less than $3 \%$ stereochemical check failures. PMDB ID for the developed Leptospira excinuclease $A B C$ subunit $B$ protein model was $P M 0076009$. Excinuclease $A B C$ subunit $B$ protein was found to be $100 \%$ identical between $L$. interrogans serovar Lai str. 56601, L. interrogans serovar Copenhageni str. Fiocruz L1-130 and 92\% identical between $L$. borgpetersenii serovar Hardjo-bovis JB197, L. borgpetersenii serovar Hardjo-bovis L550 and the predicted antigenic region was $100 \%$ conserved among all pathogenic leptospires "Fig. (5)". This revealed that Leptospira excinuclease $\mathrm{ABC}$ subunit $\mathrm{B}$ protein could generate cross protection against the four pathogenic Leptospira. During ProPred interaction studies, antigenic peptide from excinuclease $A B C$ subunit $B$ protein derived from Jemboss Antigenic server was interacting with HLA DRB1 alleles, but the whole protein was not considered for the ProPred analysis. In this view, we extended our study towards docking to confirm the interaction at 3D structural level by defining whole Leptospira excinuclease $\mathrm{ABC}$ subunit $B$ protein as ligand molecule and selected HLA DRB1 alleles as receptors. Hex 5.1 was used for docking purpose, it uses spherical polar Fourier correlations, and the acceleration of the program lies somewhere between 10 and 100 times faster than conventional FFT (Fast Fourier Transform) docking algorithms. The defined proteins were docked by setting the parameters $\mathrm{N}=20$ as steric scan and $\mathrm{N}=25$ for final searching, such parameters are well set for protein-protein docking. The complexes formed during docking were examined; the overall analysis of docking had shown favorable orientations with least binding energies viz., $583.85 \mathrm{kj} / \mathrm{mol}$ for HLA DRB1*1501- Leptospira excinuclease $A B C$ subunit $B$ protein complex with 13 Hydrogen-bonds, followed by DRB1*0401Leptospira excinuclease $A B C$ subunit $B$ protein complex with $-538.32 \mathrm{kj} / \mathrm{mol}$ involving 8 Hydrogen -bonds and then by $\mathrm{DRB} 1{ }^{*} 0101$ - Leptospira excinuclease $A B C$ subunit $B$ protein complex with
-361.02 kj/mol involving 9 Hydrogen-bonds. HLA DRB1*1501- Leptospira excinuclease ABC subunit B protein complex "Fig(6)" was found in best orientation with least binding energy ($583.85 \mathrm{kj} / \mathrm{mol}$ ) among all the complexes formed during docking. Careful analysis of $A B C$ subunit $B$ protein and three HLADRB1 binding complex revealed that the core region (136-VVIVSSVSC144) of the antigenic peptide (133REDVVIVSSVSCIYGLG-149) was well interacting with the receptors. The results suggest that interaction between Leptospira excinuclease $A B C$ subunit $B$ protein and HLA DRB1 alleles holds good at 3D structural level also. Through all these analysis and evaluation we confirmed that the antigenic peptide (133REDVVIVSSVSCIYGLG-149) of Leptospira excinuclease $A B C$ subunit $B$ protein is a T-cell driven novel subunit vaccine candidate against leptospirosis.

\section{Conclusions}

The antigen binds Class II MHC molecules, these molecules present antigen for $\mathrm{T}$ cell recognition. Leptospiral membrane proteins could elicit immunity in animal models, thus, recognizing antigenic peptides in these membrane proteins is an essential criteria for developing epitope driven vaccine against leptospirosis. These peptides could recognize $T$ cell receptor on the cell surface of CD4+ T cell. In the present study we have identified seven proteins possessing specific antigenic segments being potent to bind HLA DRB1 alleles, from which we propose antigenic peptide (133-REDVVIVSSVSCIYGLG149) of Leptospira excinuclease $A B C$ subunit $B$ protein as cross protective subunit vaccine candidate against pathogenic Leptospira. The study was carried in silico level; hence, this protein has to be presented for in vitro investigations, considering whole protein or by cloning the segment in to a vector to develop subunit vaccines against leptospirosis.

\section{Acknowledgements}

We are grateful to Department of Biotechnology (DBT), ministry of science and technology, Govt. of India for their financial assistance. Authors are Thankful to Dr. G. Subramanyam and Dr. B. Vengamma, SVIMS University.

\section{References}

[1] Levett P.N. (2001) Clinical Microbiology Reviews, 14(2), 296-326.

[2] Wang Z., Jin L. and Wegrzyn A. (2007) Microbial Cell Factories, 6, 39.

[3] Faine S.B., Adler B., Bolin C. and Perolat P. (1999) Medisci, Melbourne, Australia, 2nd edition, 193-199.

[4] Farr R.W. (1995) Clinical Infectious Diseases, 21(1), 1-6. 
[5] Romero E.C., Bernardo C.C. and Yasuda P.H. (2003) Rev Inst Med Trop Sao Paulo, 45(5), 245-248.

[6] Trueba G., Zapata S., Madrid K., Cullen P. and Haake D. (2004) International Microbiology, 7(1), 35-40.

[7] Cacciapuoti B., Vellucci A., Ciceroni L., Pinto A. and Taggi F. (1987) European Journal of Epidemiology, 3(2), 137-142.

[8] Everard C.O.R., Haynes R.J. and Edwards C.N. (1989) Epidemiology and Infection, 103(1), 143-156.

[9] Serruto D., Serino L., Masignani V. and Pizza M. (2009) Vaccine, 27(25-26), 3245-3250.

[10] Rappuoli R. (2001) Vaccine, 19(17-19), 26882691.

[11] Petrovsky N., Schonbach C. and Brusic V. (2003) In Silico Biology, 3(4), 411-416.

[12] Barker C.J., Beagley K.W., Hafner L.M. and Timms P. (2008) Vaccine, 26(10), 12851296.

[13] De Groot A.S., McMurry J., Marcon L., Franco J., Rivera D., Kutzler M., Weiner D. and Martin B. (2005) Vaccine, 23(17-18), 21212131.

[14] Panigada M., Sturniolo T., Besozzi G. Boccieri M.G., Sinigaglia F., Grassi G.G. and Grassi F. (2002) Infection and immunity, 70(1), 79-85.

[15] De Groot A.S., Bosma A., Chinai N., Frost J., Jesdale B.M., Gonzalez M.A., Martin W. and Aubin C.S. (2001) Vaccine, 19 (31), 4385-4395.

[16] Ren S.X., Fu G., Jiang X.G., Zeng R., Miao Y.G., Xu H., Zhang Y.X., Xiong H., Lu G., Lu L.F., Jiang H.Q., Jia J., Tu Y.F., Jiang J.X., Gu W.Y., Zhang Y.Q., Cai Z., Sheng H.H., Yin H.F., Zhang Y., Zhu G.F., Wan M., Huang H.L., Qian Z., Wang S.Y., Ma W., Yao Z.J., Shen Y., Qiang B.Q., Xia Q.C., Guo X.K., Danchin A., Girons I.S., Somerville R.L., Wen Y.M., Shi M.H., Chen Z., Xu J.G. and Zhao G.P. (2003) Nature, 422(6934), 888-893.

[17] Nascimento A.L., Verjovski-Almeida S., Van Sluys M.A., Monteiro-Vitorello C.B., Camargo L.E., Digiampietri L.A., Harstkeerl R.A., Ho P.L., Marques M.V., Oliveira M.C., Setubal J.C., Haake D.A. and Martins E.A. (2004) Brazilian Journal of Medical and Biological Research, 37(4), 459-477.

[18] Bulach D.M., Zuerner R.L., Wilson P., Seemann T., McGrath A., Cullen P.A., Davis J., Johnson M., Kuczek E., Alt D.P., Peterson-Burch B., Coppel R.L., Rood J.I., Davies J.K. and Adler B. (2006) PNAS, 103(39), 14560-14565.

[19] Gebriel A.M., Subramaniam G. and Sekaran S.D. (2006) Tropical Biomedicine, 23(2), 194-207.
[20] Jenkins M.K., Khoruts A., Ingulli E., Mueller D.L., McSorley S.J., Reinhardt R.L., Itano A. and Pape K.A. (2001) Annual Review of Immunology, 19, 23-45.

[21] Kuhns J.J, Batalia M.A, Yan S. and Collins E.J. (1999) Journal of biological chemistry, 274(51), 36422-36427.

[22] Watts C. (1997) Annual Review of Immunology, 15, 821-850.

[23] Chicz R.M., Urban R.G., Lane W.S., Gorga J.C., Stern L.J., Vignali D.A. and Strominger J. L. (1992) Nature, 358, (6389), 764-768.

[24] Rudensky A., Hurlburt P.P., Hong S.C., Barlow A. and Janeway C.A. (1991) Nature, 353 (6345), 622-627.

[25] Rudolph M.G. and Wilson I.A. (2002) Current Opinion in Immunology, 14(1), 52-65.

[26] Serruto D. and Rappuoli R. (2006) FEBS Letters, 580(12), 2985-2992.

[27] Carver T. and Bleasby A. (2003) Bioinformatics, 19(14), 1837-1843.

[28] Kolaskar A.S. and Tongaonkar P.C. (1990) FEBS Letters, 276(1-2), 172-174.

[29] Singh H. and Raghava G.P.S. (2001) Bioinformatics, 17(12), 1236-1237.

[30] Sturniolo T., Bono E., Ding J., Raddrizzani L., Tuereci O., Sahin U., Braxenthaler M., Gallazzi F., Protti M.P., Sinigaglia F. and Hammer J. (1999) Nature Biotechnology, 17(6), 555-561.

[31] Altschul S.F., Madden T.L., Schaffer A.A., Zhang J., Zhang Z., Miller W. and Lipman D.J. (1997) Nucleic Acids Research, 25(17), 3389-3402.

[32] Berman H.L., Westbrook J., Feng Z., Gilliland G., Bhat T.N., Weissig H., Shindyalov I.N. and Bourne P. E. (2000) Nucleic Acids Research, 28(1), 235-242.

[33] Thompson J.D., Gibson T.J., Plewniak F., Jeanmougin F. and Higgins D.G. (1997) Nucleic Acids Research, 25(24), 48764882.

[34] Sali A. and Blundell T.L. (1993) Journal of Molecular Biology, 234(3), 779-815.

[35] Laskowski R.A., MacArthur M.W., Moss D.S. and Thornton J. M. (1993) Journal of Applied Crystallography, 26(2), 283-291.

[36] Wiederstein M. and Sippl M.J. (2007) Nucleic Acids Research, 35, 407-410.

[37] Wallner B. and Elofsson A. (2003) Protein Science, 12(5), 1073-1086.

[38] Castrignano T., De Meo P.D.O., Cozzetto D., Talamo I.G. and Tramontano A. (2006) Nucleic Acids Research, 34, 306-309.

[39] Ritchie D.W., Kozakov D. and Vajda S. (2008) Bioinformatics, 24(17), 1865-1873.

[40] Bryson K., McGuffin L.J., Marsden R.L., Ward J.J., Sodhi, J.S. and Jones, D.T. (2005) Nucleic Acids Research, 33, 36-38. 
Table 1- Antigenic peptides from of L. interrogans serovar Lai Jemboss output showing core epitope region binding with HLA DRB1 alleles

\begin{tabular}{|c|c|c|c|c|c|c|c|c|c|}
\hline \multirow{2}{*}{$\begin{array}{l}\text { SI. } \\
\text { no. }\end{array}$} & \multirow[t]{2}{*}{ GenBank ID } & \multicolumn{3}{|c|}{ Jemboss result } & \multicolumn{5}{|c|}{ ProPred result (score) } \\
\hline & & Antigenic Site & Region & Score & Epitope & $\begin{array}{l}\text { HLA1 } \\
{ }^{*} 0101 \\
\end{array}$ & $\begin{array}{l}\text { HLA1 } \\
{ }^{*} 0401 \\
\end{array}$ & $\begin{array}{l}\text { HLA1 } \\
{ }^{*} 1501 \\
\end{array}$ & Average \\
\hline 1 & AAN48647.1 & DRVYPRKLFLFVLLLFVFQCSSP & $9->31$ & 1.243 & VLLLFVFQC & 18.33 & 19.77 & 36.73 & 24.94 \\
\hline 2 & AAN48927.1 & FLRISVCLLLLFVGHT & $4->19$ & 1.269 & LRISVCLLL & 46.67 & 37.21 & 59.18 & 47.69 \\
\hline 3 & AAN49594.1 & $\begin{array}{l}\text { EKYLPIGGYVLFLAVGLLLFFSAA } \\
\text { FLVVFVRTK }\end{array}$ & $8->40$ & 1.235 & YVLFLAVGL & 73 & 14.88 & 54.08 & 47.32 \\
\hline \multirow[t]{2}{*}{4} & AAN48596.1 & $\begin{array}{l}\text { GSLILFANLIKIVQREGVIAFLSTL } \\
\text { VLVVIVLILFFRGIVPALISLIPLVL } \\
\text { GIFVTLGIM }\end{array}$ & $752->811$ & 1.312 & LGIFVTLGI & 14.67 & 27.91 & 71.02 & 37.87 \\
\hline & & KPGLLTLVVIIVVLMISFFN & $472->491$ & 1.298 & VVIIVVLMI & 50 & 54.65 & 66.33 & 56.99 \\
\hline \multirow[t]{3}{*}{5} & AAN48742.1 & $\begin{array}{l}\text { EAAILVVIVLIIALGTVKGALLVAL } \\
\text { AIPIPMLTAT }\end{array}$ & $343->377$ & 1.279 & IVLIIALGT & 45 & 27.91 & 55.1 & 42.67 \\
\hline & & $\begin{array}{l}\text { AFGSIYYALGVFIVVPLAVSGGII } \\
\text { GLVIRGLPFSIPAGVGFIAVSGIA } \\
\text { VLNGVVYAST }\end{array}$ & $890->947$ & 1.244 & VFIVVPLAV & 27.5 & 4.65 & 45.92 & 26.02 \\
\hline & & $\begin{array}{l}\text { TDACVRVGRAAAFSVAIILLVYLP } \\
\text { LMSLEG }\end{array}$ & $440->469$ & 1.233 & LVYLPLMSL & 23.17 & 16.28 & 59.18 & 32.88 \\
\hline 6 & AAN49754.1 & $\begin{array}{l}\text { FTAIIASATAGLIGSILYIFGFSSVI } \\
\text { VLVLVAALLIFLFGR }\end{array}$ & $458->498$ & 1.312 & LVLVAALLI & 50.83 & 18.6 & 60.2 & 43.21 \\
\hline 7 & AAN47848.1 & REDVVIVSSVSCIYGLG & $133->149$ & 1.244 & VVIVSSVSC & 44.17 & 32.33 & 47.96 & 41.49 \\
\hline
\end{tabular}

* Sixth column in the table represents common core epitope region of individual antigenic peptide binding with the selected HLA DRB alleles

Table 2- Comparison of validation reports of Leptospira excinuclease $A B C$ subunit B protein modal and crystal structure 2D7D template

\begin{tabular}{|l|c|c|}
\hline Amino acid position & $\begin{array}{c}\text { Modeled } \\
\text { protein } \\
(\%)\end{array}$ & $\begin{array}{c}\text { 2D7D template } \\
\text { structure (\%) }\end{array}$ \\
\hline Most favored region & 93.6 & 93 \\
\hline Additional allowed region & 5.6 & 6.5 \\
\hline Generously allowed region & 0.7 & 0.5 \\
\hline Disallowed region & 0.2 & 0.0 \\
\hline
\end{tabular}




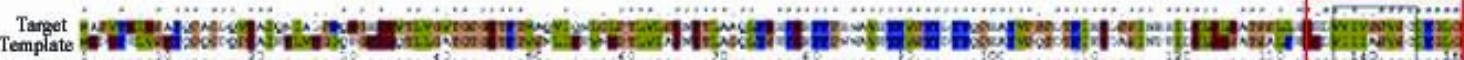

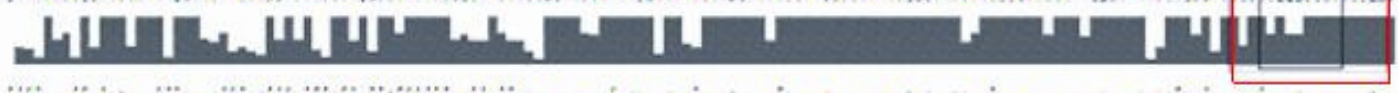

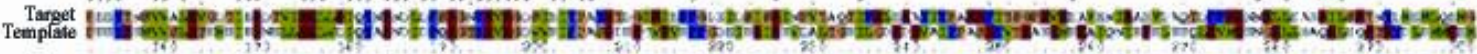

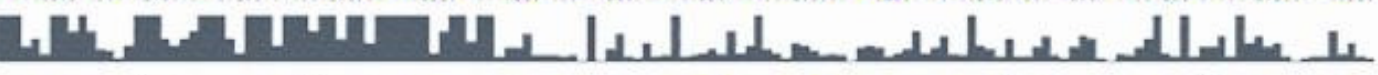

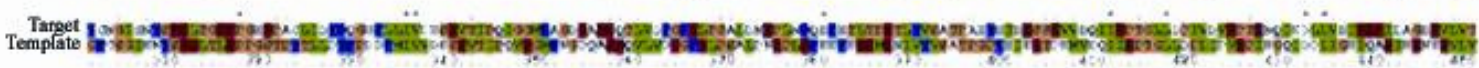

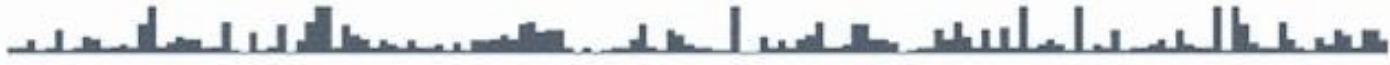

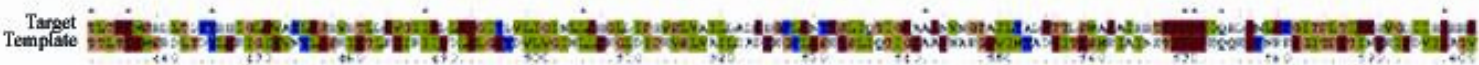

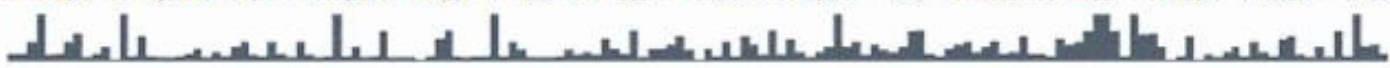

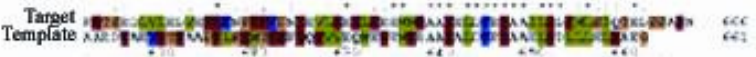

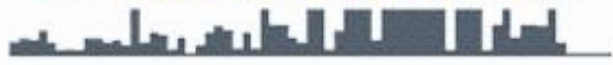

Fig. 1- ClustalX [33] alignment of target and template sequences ( $60 \%$ identity, $75 \%$ similarity and $0 \%$ gaps). The red box indicates alignment of antigenic peptide and the black box shows alignment of T-cell core epitope region

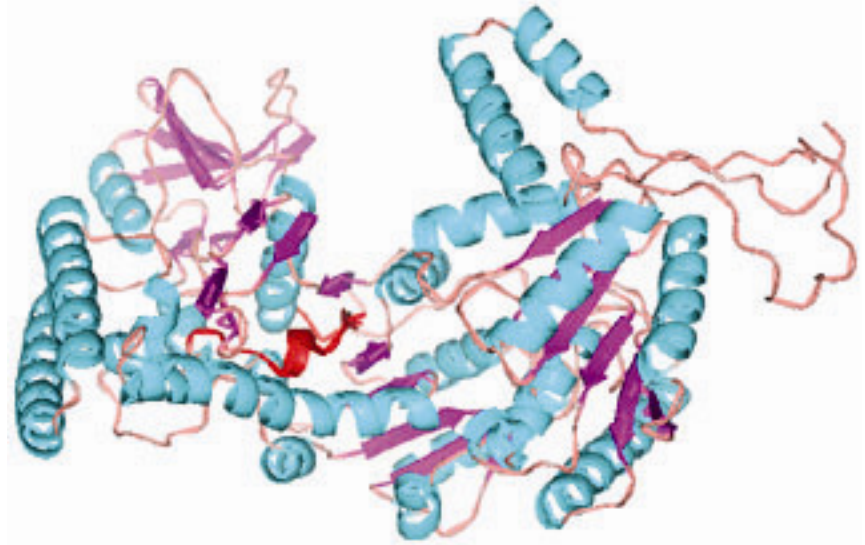

Fig. 2- PyMOL (DeLano Scientific LLC, 2009) view of Leptospira excinuclease ABC subunit B protein. The region (133149) shown in red is the antigenic site

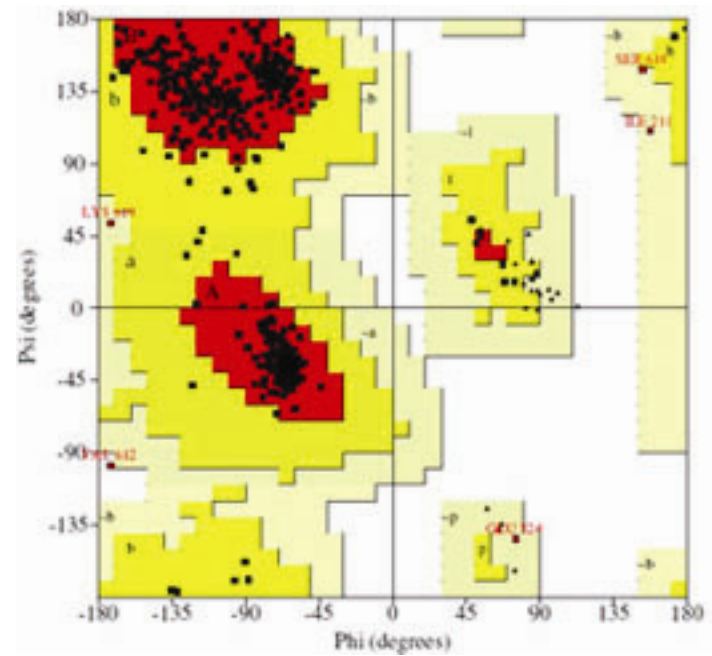

Fig. 3- Procheck [35] validation report of Leptospira excinuclease ABC subunit B protein model. 93.6\% residues in most favored region, $5.6 \%$ in additional allowed region and $0.7 \%$ in generously allowed region 

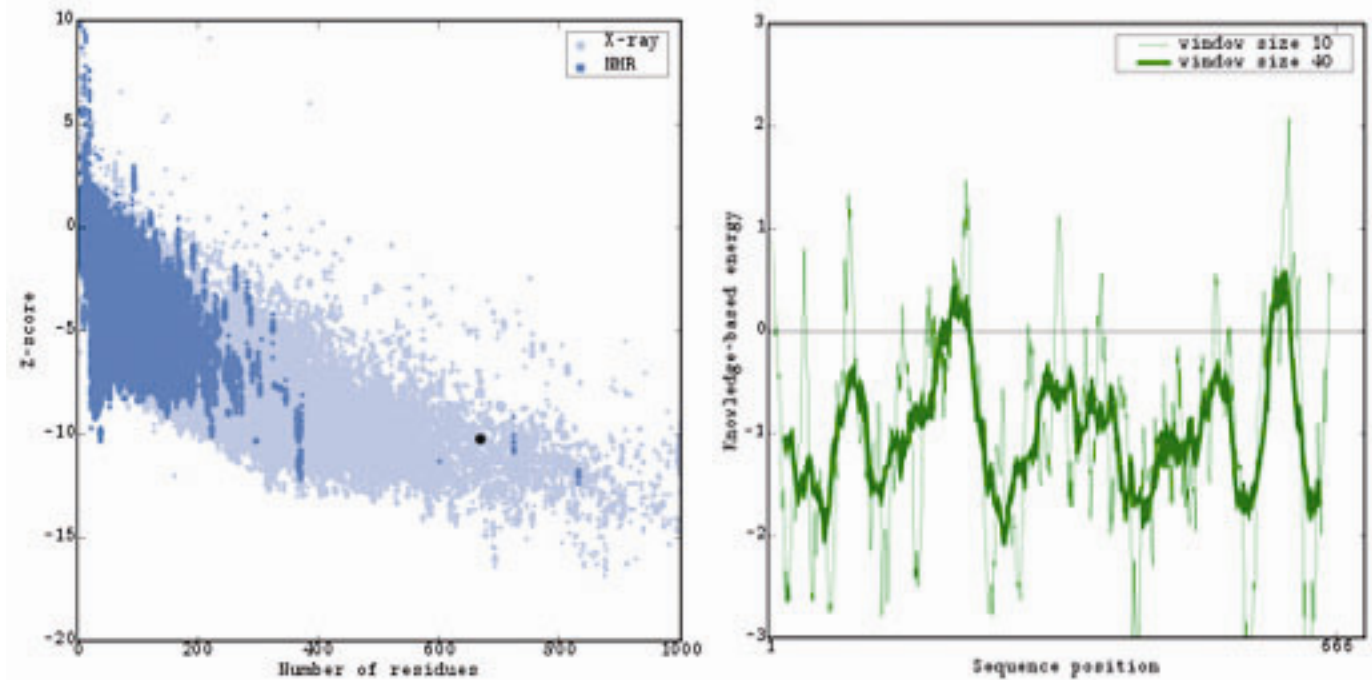

Fig. 4- Pro-SA web [36] validation of the modeled Leptospira excinuclease ABC subunit B protein (A) ProSA-web Zscores score of Leptospira excinuclease $\mathrm{ABC}$ subunit $\mathrm{B}$ protein was present in the range of native $\mathrm{X}$-ray crystal structure represented in black dot. $(Z$ score $=-10.19)(B)$ Energy plot for the predicted Leptospira excinuclease $A B C$ subunit $B$ protein

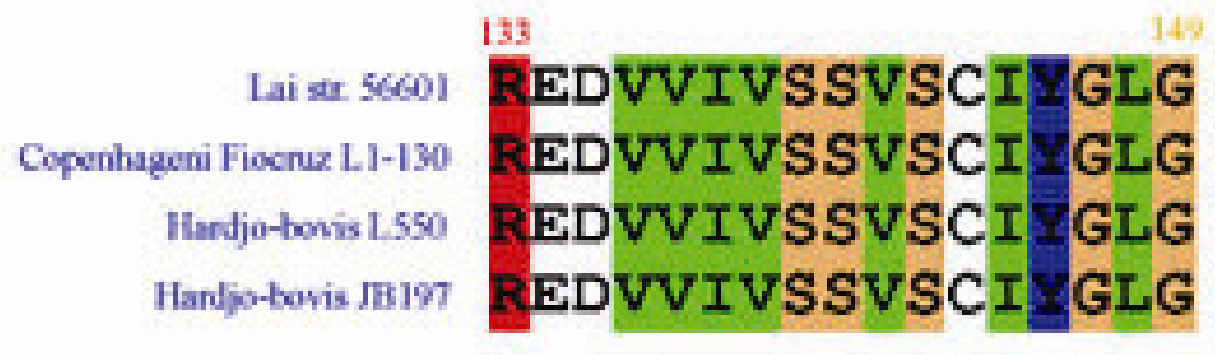

Fig. 5- ClustalX [33] alignment of four pathogenic Leptospira excinuclease ABC subunit B proteins showing $100 \%$ conserved antigenic region

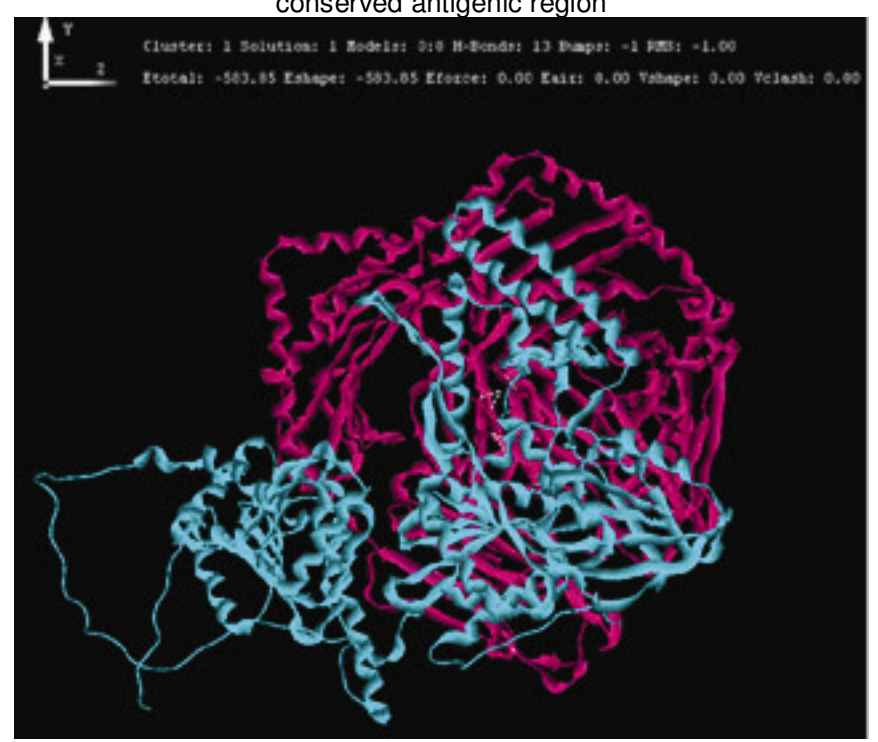

Fig. 6- HLA DRB1*1501 and Leptospira excinuclease ABC subunit B protein complex in best orientation with least binding energy $(-583.85 \mathrm{kj} / \mathrm{mol})$ [39]. Complete antigenic site was involved in the interaction, overall proteins were found to be interacting with 13 hydrogen bonds represented with white dotted lines 